\title{
NOVEL CATIONIC AND HYDROPHOBIC PULLULAN DERIVATIVES AS DNA NANOPARTICULATE CARRIERS
}

\author{
MARIETA CONSTANTIN, ${ }^{*}$ SANDA BUCATARIU, ${ }^{*}$ LAURA URSU, ${ }^{* *}$ MARIA BUTNARU, ${ }^{* * *}$ OANA \\ MARIA DARABA,${ }^{* * * *}$ ALEXANDRA MARIA BURLUI ${ }^{* * * *}$ and \\ GHEORGHE FUNDUEANU* \\ "Department of Natural Polymers, Bioactive and Biocompatible Materials, "Petru Poni" Institute of \\ Macromolecular Chemistry, 41A, Gr. Ghica Voda Alley, 700487 Iasi, Romania \\ ** Centre of Advanced Research in Bionanoconjugates and Biopolymers, "Petru Poni" Institute of \\ Macromolecular Chemistry, 41A, Gr. Ghica Voda Alley, 700487 Iasi, Romania \\ *:* Faculty of Medical Bioengineering, "Gr. T. Popa” University of Medicine and \\ Pharmacy, 16, University Str., 700115 Iasi, Romania \\ ****: Domenico Medical Center SRL, 11 Pacurari Str., 700511 Iasi, Romania \\ ¿Corresponding author: M. Constantin, marieta@icmpp.ro
}

Received March 21, 2019

\begin{abstract}
A novel cationic associating pullulan derivative (DBAP-P) was synthesized using pullulan as hydrophilic backbone and (dibuthylamino)propyl carbamate groups as pendant cationic and hydrophobic segments. The structural characteristics of this polymer were investigated by FT-IR, ${ }^{1} \mathrm{H}$ - and ${ }^{13} \mathrm{C}-\mathrm{NMR}$ spectroscopy. The degree of substitution was found to be 0.36 cationic moieties per structural unit of pullulan.

The intrinsic viscosity of the DBAP-P sample was calculated using Fedors' and Wolf's models. The critical aggregation concentration $(c a c)$ value of $0.1 \mathrm{~g} / \mathrm{dL}$ determined by fluorescence measurements in the presence of pyrene, as probe, was confirmed by capillary viscosimetry and dynamic laser scattering (DLS). DNA was loaded into the DBAP-P particles by the osmosis based method. The mean diameter and zeta potential of DNA-loaded particles in aqueous solutions, as determined by DLS, decreased with increasing the DNA/DBAP-P ratio for the same polymer concentration. AFM images demonstrated that the DBAP-P and DNA-loaded DBAP-P nanoparticles had a spherical shape.
\end{abstract}

Keywords: cationic pullulan, associating polymer, viscometry, fluorescence, DNA carrier

\section{INTRODUCTION}

A growing interest is being given to amphiphilic polymers due to their potential in biotechnological and pharmaceutical uses. ${ }^{1,2}$ In aqueous solutions, these polymers can form spontaneously micelles or micelle-like aggregates, mainly through intra- and/or intermolecular interactions between hydrophobic and hydrophilic chains. Having a hydrophobic core and a hydrophilic shell, polymeric micelles have been used especially as drug carriers.

Cationic polysaccharides have a large application domain due to their hydrophilicity, biodegradability and antibacterial properties. They are used as drug and gene delivery systems, ${ }^{3-5} \quad$ flocculants, ${ }^{6-8}$ chromatography supports ${ }^{9}$ and as bacterial and cellular adhesion modifiers. ${ }^{10}$ The polysaccharides can be chemically modified by replacing hydroxyl groups with amino groups, while maintaining the polymeric structure. Etherification with 2hydroxy-3-(N,N,N-trimethylammonium)propyl groups has been most commonly applied method to introduce cationic groups into polysaccharides, ${ }^{11-14}$ but tertiary amine groups ${ }^{15,16}$ were also introduced. Some cationic hydrophobically modified polysaccharides show an auto-associative character due to the presence of cationic charges and hydrophobic groups on the macromolecular chain; their aggregation has been controlled by the balance between the hydrophobic and electrostatic interactions. Amphiphilic polysaccharides are prepared by the quaternisation reaction ${ }^{17-20}$ or reductive amination $^{21,22}$ and are obtained generally by 
combining the cationic character of the ammonium function and the hydrophobic character of alkyl chains.

Pullulan (P) is a neutral, water-soluble polysaccharide produced from starch by the fungus Aureobasidium pullulans, by means of a process of fermentation. ${ }^{23}$ Due to its interesting properties, such as chemical flexibility, physiological activity, adhesive ability, and capacity to form fibers and thin biodegradable films, ${ }^{24}$ this polymer presents an increasing interest as a material for drug and gene nanocarriers. $^{23-28}$ The best known nanocarrier based on pullulan is cholesteryl-pullulan, which forms nanocomplexes with both hydrophobic and hydrophilic drugs, such as proteins (i.e. insulin, bovine serum albumin, DNA, IL-12). ${ }^{23,25-29}$ Besides hydrophobically modified pullulan-based nanoparticles, proteins have been loaded in polyplexes $^{28,30}$ or in a $3 D$-matrix ${ }^{3}$ based on cationic pullulan derivatives.

In order to widen the range of cationic polysaccharides designed to produce drug-loading nanoparticles, we propose the synthesis of a new cationic amphiphilic pullulan derivative. We report its aqueous solution behavior in the dilute and semi-dilute concentration regime by zeta potential, hydrodynamic diameter, fluorescence and viscosity measurements. Finally, since the polyplexes cannot be obtained with well-defined nanostructured morphology, we used the new osmosis-based method reported by Masotti et al. ${ }^{31}$

for producing spherical DNA-loaded polymeric nanoparticles.

\section{EXPERIMENTAL}

Materials

Pullulan $(\mathrm{P})(\mathrm{Mw}=200,000 \mathrm{~g} / \mathrm{mol})$ was purchased from from Hayashibara Lab. Ltd. (Okoyama, Japan). 3-(Dibutylamino)propylamine (DBAPA) and N,N'carbonyldiimidazole (CDI) were purchased from Fluka (Buchs, Switzerland) and used as such.

Dimetyl sulfoxide (DMSO) was supplied by Sigma-Aldrich Co. (St. Louis, USA) and distilled under vacuum prior to use. Tetrahydrofuran (THF) was received from Sigma-Aldrich Co. (St. Louis, USA) and was maintained on 3A molecular sieve prior to use.

Deoxyribonucleic acid (low molecular weight, from salmon sperm) (DNA) and pyrene (Py) were both purchased from Sigma-Aldrich Co. (St. Louis, USA) and were used as such.

\section{Methods}

Synthesis of (dibutylamino)propyl carbamate pullulan (DBAP-P)

The synthesis of DBAP-P was realized in two steps as described below.

1) Briefly, $0.75 \mathrm{~g}$ of CDI (molar ratio of CDI to anhydroglucose unit (AGU) of pullulan was 0.75:1) was added to a certain volume of THF. Then, an equimolar amount of DBAPA $(1.04 \mathrm{~mL})$ solved in THF was added dropwise and the reaction was carried out for $24 \mathrm{~h}$ under magnetic stirring at room temperature. The intermediate (1, Scheme 1) was recovered from the solution by evaporation to dryness using a rotary evaporator and was subsequently redissolved in an appropriate volume of dry DMSO to be used in the next step.

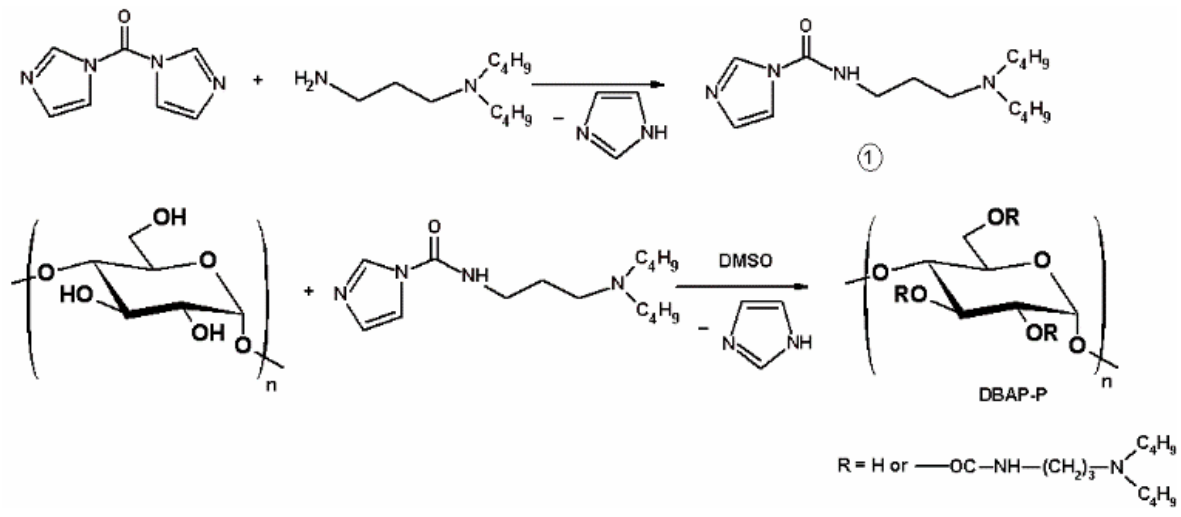

Scheme 1: Synthesis route of cationic pullulan derivative

2) In a round bottom flask fitted with 2 necks, $1 \mathrm{~g}$ of dried pullulan (P) was dissolved in an appropriate volume of DMSO $(5 \%, w / v)$ and then, the DMSO solution of $\mathbf{1}$ was added dropwise. The reaction was carried out for $24 \mathrm{~h}$ at $80{ }^{\circ} \mathrm{C}$ in an oil bath, under stirring at $300 \mathrm{rpm}$. The derivative DBAP-P was recovered by precipitation in acetone. The precipitate was resolubilized in distilled water, dialyzed against acidic and then alkaline water to remove unreacted DBAPA, afterwards against distilled water until total 
deionization (checked by conductivity measurement in the dialysis water). Finally, the polymer was recovered by freeze-drying.

\section{Formation of DBAP-P and DBAP-P/DNA nanoparticles}

The osmosis method was used to prepare DNA free and loaded polymeric nanoparticles by using different solvent pairs (i.e. $\mathrm{H}_{2} \mathrm{O} / \mathrm{MeOH}, \mathrm{H}_{2} \mathrm{O}$ /acetone, $\left.\mathrm{H}_{2} \mathrm{O} / \mathrm{CH}_{3} \mathrm{CN}\right){ }^{32}$ Briefly, $25 \mathrm{mg}$ DBAP-P was dissolved in $5 \mathrm{~mL}$ of distilled water. The solution was transferred to a dialysis bag (molecular weight cut off 10,000 $12,000 \mathrm{Da}$; from Medicell International, London, United Kingdom) and immersed into methanol (100 $\mathrm{mL}$ ), selected as the best non-solvent for polymer precipitation in the form of spherical nanoparticles. After $72 \mathrm{~h}$, the precipitated polymer was recovered, washed several times with methanol, and then the pellet was freeze-dried.

The DNA-loaded nanoparticles were prepared by adding $1 \mathrm{~mL}$ of aqueous solution of DNA (in specific ratios), preheated to $50{ }^{\circ} \mathrm{C}$, to a solution of $25 \mathrm{mg}$ DBAP-P dissolved in $4 \mathrm{~mL}$ of distilled water, under vigorous stirring. The mixture was then dialyzed against methanol, as described above for DBAP-P nanoparticle preparation.

In order to evaluate the DNA contents, freeze-dried DBAP-P/DNA nanoparticles $(10 \mathrm{mg})$ suspended in 5 $\mathrm{mL}$ of phosphate buffer (PBS, $\mathrm{pH}=7.4$ ) containing 0.5 $\mathrm{M} \mathrm{NaCl}$ were placed in a dialysis bag and dialyzed against this medium. Periodically, the release medium was pipetted out and the same fresh medium was replaced up to their complete dissolution. The final release medium collected was analysed for DNA content by spectrophotometric measurements (Evolution 201 UV spectrophotometer, Thermo Fisher Scientific Inc., Madison, USA) at $260 \mathrm{~nm}$.

The drug loading content (DLC) and entrapment efficiency (EE) of nanoparticles (NPs) were calculated according to Equations (1) and (2), respectively:

$$
\begin{aligned}
& D L C\left(\text { wt. \%) }=\frac{\text { Amount of DNA in Nps }}{\text { Weight of Nps }} \times 100\right. \\
& E E(\%)=\frac{\text { Amount of DNA in Nps }}{\text { Feeding amount of DNA }} \times 100
\end{aligned}
$$

\section{In vitro cytotoxicity}

The cytotoxicity of the DBAP-P samples and DNA-loaded DBAP-P nanoparticles was examined by MTT assay. Primary albino rabbit dermal fibroblasts were seeded in 48-well culture plates at $1 \times 10^{4}$ cells/well and cultured for 1 day in DMEM/Ham-F12 medium, containing $10 \% \mathrm{FBS}$ and $1 \% \mathrm{P} / \mathrm{S} / \mathrm{N}$, at $37{ }^{\circ} \mathrm{C}$, $5 \% \mathrm{CO}_{2}$ and humidified atmosphere. After reaching $90 \%$ confluency, the cells were incubated with different concentrations of the DBAP-P or DNAloaded DBAP-P nanoparticles in water $(25 \mu \mathrm{g} / \mathrm{mL}, 50$ $\mu \mathrm{g} / \mathrm{mL}$ and $100 \mu \mathrm{g} / \mathrm{mL}$ ) for 1,2 or 3 days. The medium was replaced with $500 \mu \mathrm{L}$ of $0.25 \mathrm{mg} / \mathrm{mL}$ MTT work solution and incubated for 3 hours. After that, the medium was removed and replaced with $500 \mu \mathrm{L}$ of isopropanol, to solubilize the insoluble formazan crystals. The absorbance was measured at $570 \mathrm{~nm}$ using a microplate reader (Tecan UV-VIS, Switzerland). Triplicate samples were analyzed for each experiment. The relative cell viability was calculated according to Equation (3):

Cell viability $(\%)=\left[O D_{570}(\right.$ samples $) / O D_{570}($ control $\left.)\right] \times 100$

where $O D_{570}$ (control) was obtained in the absence of polymers, but in the presence of an equivalent water volume and $O D_{570}$ (samples) was obtained in the presence of samples.

The cell morphology of the unstained cells was analysed after 72 hours of incubation by phase-contrast microscopy (Leica DMIL inverted microscope, Germany).

\section{Characterization}

FT-IR spectra of P and DBAP-P were obtained on a Bruker Vertex 7 FT-IR spectrometer. The samples were analyzed in solid (lyophilized) state on a KRS-5 support, within the frequency range of $4000-600 \mathrm{~cm}^{-1}$. Data processing was done using the OPUS 6.5 software (Bruker Optics).

${ }^{1} \mathrm{H}-\mathrm{NMR}$ spectra of $\mathrm{P}$ and DBAP-P samples in $\mathrm{D}_{2} \mathrm{O}$ were recorded on a Bruker Avance DRX 400 NMR spectrometer (Rheinstetten, Germany) at $25^{\circ} \mathrm{C}$.

The hydrodynamic diameter $\left(\mathrm{D}_{\mathrm{h}}\right)$ and size distribution of the aggregates of DBAP-P in distilled water were measured on a ZetasizerNano ZS (Malvern Zetasizer NS-Malvern Instruments, Malvern, UK) at $25{ }^{\circ} \mathrm{C}$ and $40{ }^{\circ} \mathrm{C}$ by DLS technique. $\zeta$-Potential measurements were also carried out at $25{ }^{\circ} \mathrm{C}$ using a Zetasizer Nano ZS at $90^{\circ}$ detection angle. The reported data are means of 5 separate measurements. The DLS technique was also used for the measurement of the size and polydispersity index of DBAP-P and DBAPP/DNA nanoparticles in distilled water at $1 \mathrm{mg} / \mathrm{mL}$ concentration and $25^{\circ} \mathrm{C}$.

The morphological observation of DBAP-P and DBAP-P/DNA nanoparticles was performed by AFM, using an Ntegra Spectra-NT-MDT (Russia) instrument. The samples were prepared by dropping $10 \mu \mathrm{L}$ of nanoparticle solution on freshly cleaved mica $(\mathrm{C}=0.1$ $\mathrm{mg} / \mathrm{mL}$ ), followed by natural drying for $24 \mathrm{~h}$.

\section{Determination of critical aggregation concentration (cac)}

Polymer solutions with concentrations varying from 0.01 to $2 \mathrm{~g} / \mathrm{dL}$, containing $2 \times 10^{-6} \mathrm{M}$ pyrene (a value slightly lower than its solubility in water ${ }^{32}$ ) were prepared.

Steady-state fluorescence emission spectra were recorded on a LS 55 PerkinElmer fluorescence spectrometer (Waltham, Massachusetts, United States). For measurement of the intensity ratio of the first and third vibronic peaks of pyrene, the slit openings for 
excitation and emission were 8 and $2.5 \mathrm{~mm}$ (the excitation wavelength $\lambda_{\text {ex }}$ was $335 \mathrm{~nm}$ ) and the emission spectra were recorded from 360 to $390 \mathrm{~nm}$. The onset of polymer aggregation (critical aggregation concentration $(c a c)$ ) was determined from the intersection of the tangent to the curve at the inflection with the horizontal tangent through the points at low concentration.

\section{Viscometric behavior}

Viscosity measurements were performed on a SCHOTT AVS 350 viscometer (Ubbelohde viscometer, with type 0a capillary), equipped with an optical system for flow detection. The temperature was controlled by a water bath and maintained at $25.0 \pm 0.1{ }^{\circ} \mathrm{C}$. For the measurements, a stock solution of polymer $(2 \mathrm{~g} / \mathrm{dL})$ was prepared in deionized water and used to prepare $10.0 \mathrm{~mL}$ of each more dilute solution.

\section{RESULTS AND DISCUSSION}

Synthesis and chemical characterization of DBAP-P derivative

Synthesis of the pullulan derivative with tertiary amine groups (N,N-dibutylamino-1,3propyl) was performed under mild conditions by activation of the amine with $\mathrm{N}, \mathrm{N}$ carbonyldiimidazole (CDI) and its subsequent conjugation with the hydroxyl groups of pullulan (Scheme 1). The reaction took place in DMSO medium, which is a good solvent for most polysaccharides, ${ }^{33}$ without leading to secondary reaction products.

Figure 1 shows the FTIR spectra for $\mathrm{P}$ and DBAP-P. As compared with the P spectrum, the DBAP-P spectrum presents a characteristic band at $3400 \mathrm{~cm}^{-1}$, which was attributed to the $\mathrm{O}-\mathrm{H}$ and $\mathrm{N}-\mathrm{H}$ groups stretching vibrations. The $\mathrm{C}-\mathrm{H}$ stretching vibration peaks from the tertiary amine groups introduced were observed at 2875 and $2790 \mathrm{~cm}^{-1}$. New absorption bands, characteristic of asymmetric and symmetric C-H from methylene groups, are observed at 2933 and 2958 $\mathrm{cm}^{-1}$. The appearance of the bands at $1704 \mathrm{~cm}^{-1}$ $(\mathrm{C}=\mathrm{O}$ vibration absorption peak, amide band $\mathrm{I})$, $1541 \mathrm{~cm}^{-1}$ (the amide band II caused by N-H and C-N coupling) and $1364 \mathrm{~cm}^{-1}$ (amide band III) was the evidence for the cationization of pullulan by an amide group.

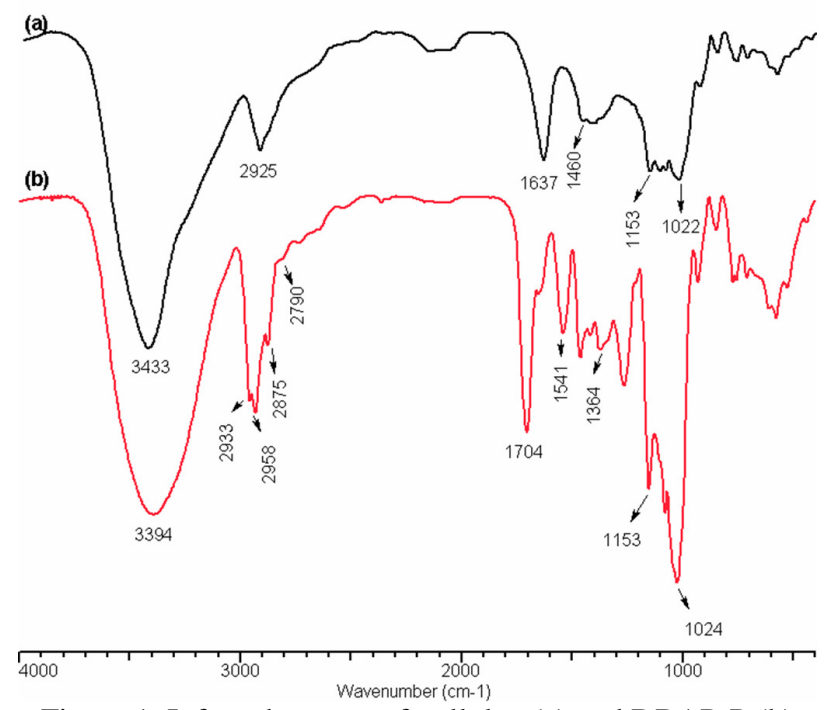

Figure 1: Infrared spectra of pullulan (a) and DBAP-P (b)

Figure 2 shows the ${ }^{1} \mathrm{H}$ - and ${ }^{13} \mathrm{C}$-NMR spectra for DBAPA-P. The ${ }^{1} \mathrm{H}-\mathrm{NMR}$ spectrum of the cationic derivative showed the six protons of the terminal methyl groups of the butyl chain as a double triplet around $0.92 \mathrm{ppm}$. The protons of the methylene groups in the butyl chain appeared at $1.37 \mathrm{ppm}\left(4 \mathrm{H},-\mathrm{N}\left(\mathrm{CH}_{2}-\mathrm{CH}_{2}-\mathrm{CH}_{2}-\right)_{2} ; 1.62 \mathrm{ppm}\right.$
(4H, $\left.-\mathrm{N}\left(\mathrm{CH}_{2}-\mathrm{CH}_{2}-\mathrm{CH}_{2}-\right)_{2}\right)$ and $3.06 \mathrm{ppm}(4 \mathrm{H}$, $\left.\mathrm{N}\left(\mathrm{CH}_{2}-\mathrm{CH}_{2}-\mathrm{CH}_{2}-\right)_{2}\right)$ along with the two methylene protons $\left(2 \mathrm{H},-\mathrm{CH}_{2}-\mathrm{N}\right)$. The other signals were assigned to the $-\mathrm{CH}_{2}$ protons of the propyl group $(1.89 \mathrm{ppm})$ and the $\mathrm{NH}-\mathrm{CH}_{2-}$ protons (3.22 ppm). Additionally, the ${ }^{1} \mathrm{H}-\mathrm{NMR}$ spectrum of the cationic derivative revealed the 
presence of the $(1 \rightarrow 6)$ and $(1 \rightarrow 4)$ anomeric protons at $4.98 \mathrm{ppm}, 5.38$ and $5.42 \mathrm{ppm}$. The signals between 3.3 and 4.04 ppm were assigned to the hydrogen atoms in pullulan. ${ }^{34}$ Thus, the substitution degree (DS, number of amino groups per anhydroglucose unit in pullulan) could be determined from the ratio of the normalized, integrated intensities of the signals of the six protons of the terminal methyl group of the butyl chain to the H-1 protons of pullulan moieties and it was found to be 0.36 .
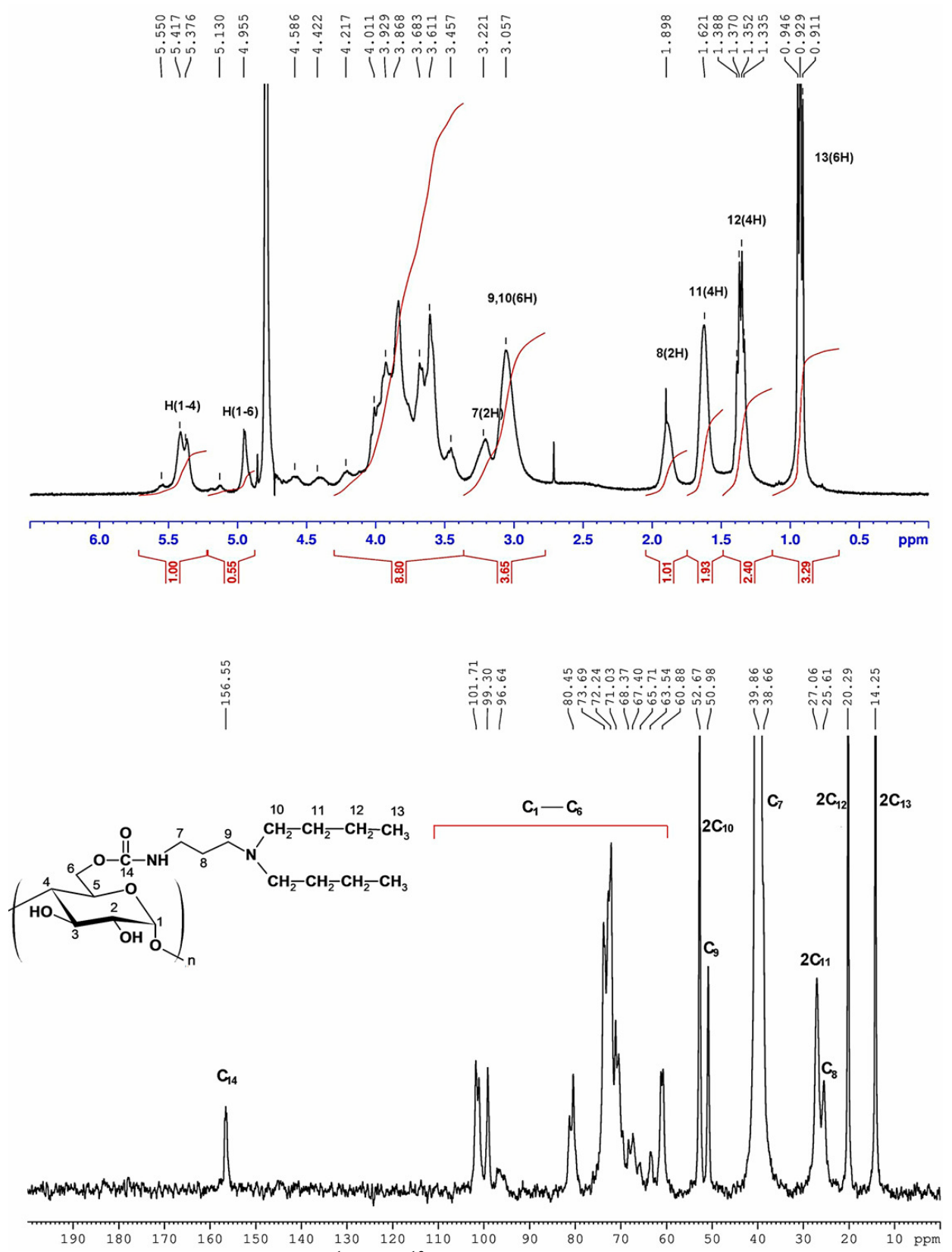

Figure 2: ${ }^{1} \mathrm{H}$ and ${ }^{13} \mathrm{C}-\mathrm{NMR}$ spectra for DBAP-P

In the ${ }^{13} \mathrm{C}-\mathrm{NMR}$ spectrum of DBAP-P (Fig. 2), a decrease in the signals, corresponding to the carbon from 6 position at 60.9 ppm $\left(\mathrm{C}-6_{\mathrm{OH}}\right.$ for pullulan), was observed, as well as the appearance of a new signal at $63.5 \mathrm{ppm}$ corresponding to the
C-6-substituted one. This indicated that the functionalization of pullulan occurred at $\mathrm{C}-6$. The other signals appeared at $14.2 \mathrm{ppm}\left(\mathrm{C}-13, \mathrm{CH}_{3}\right)$, $20.3 \mathrm{ppm}\left(\mathrm{C}-12, \mathrm{CH}_{2}\right), 25.6 \mathrm{ppm}\left(\mathrm{C}-8, \mathrm{CH}_{2}\right)$, $27.06 \mathrm{ppm}\left(\mathrm{C}-11, \mathrm{CH}_{2}\right), 38.6 \mathrm{ppm}(\mathrm{C}-7, \mathrm{C}-\mathrm{NH})$, 
50.9 ppm $\left(\mathrm{C}-9, \mathrm{CH}_{2}\right), 52.6$ ppm $\left(\mathrm{C}-10, \mathrm{CH}_{2}-\mathrm{N}\right)$. Additionally, the splitting of the carbonyl signal at $156.5 \mathrm{ppm}(\mathrm{C}-14, \mathrm{C}=\mathrm{O}$ in the carbamate group), as well as those of 101.7 and $99.3 \mathrm{ppm}$, which correspond to the $\mathrm{C}-1$ carbon atom, indicated that the functionalization took place to a certain degree at position $\mathrm{C}-2$ of the pullulan structural unit.

\section{Viscosities of aqueous solutions}

Viscometry can offer valuable information about the behavior of polymer chains in solution (i.e. the interactions between polymer chains or with solvent molecules, the flexibility and some hydrodynamic parameters of the polymer chains in solution).

DBAP-P has moderate hydrophobic charged groups, carbamate bonds, and the hydrophobic propyl moieties, randomly distributed along the hydrophilic pullulan chain, and its viscosity behavior will be determined by the electrostatic, hydrogen bonding, and intra- and inter-molecular hydrophobic interactions. Nichifor et al. ${ }^{35}$ found that, for amphiphilic polymers, the occurrence of intermolecular aggregates in the dilute domain cannot be neglected, therefore the magnitude of intrinsic viscosity $[\eta]$ will not reflect the size and conformation of a single polymer chain.

Figure 3 presents the plots of reduced viscosities as a function of polymer concentration in aqueous solutions of pullulan and DBAP-P derivative. For the pullulan sample, the dependence is linear over the investigated range of concentrations and, according to Huggins' method (Eq. (4)), the extrapolation to infinite dilution gives a value of $0.615 \mathrm{dL} / \mathrm{g}$ for the intrinsic viscosity and from the slope, it follows that $k_{\mathrm{H}}=0.59$ :

$$
\eta_{s p} / C=[\eta]+k_{H}[\eta]^{2} C
$$

where $\eta_{\mathrm{sp}} / C$ is the reduced viscosity (with $\eta_{\mathrm{sp}}=\eta_{\mathrm{r}}$ - 1 , the specific viscosity and $\eta_{\mathrm{r}}=$ the relative viscosity).

The plot obtained for the DBAP-P derivative shows a nonlinear shape, a typical behavior of polyelectrolyte solutions, characterized by a continuous increase in reduced viscosity with dilution. Also, the viscosity of the modified polymer is higher than that of the parent pullulan, probably due to the electrostatic repulsions between charges and/or intermolecular hydrophobic interactions.

Since the determination of the intrinsic viscosity employing the extrapolation to zero concentration was not possible, this problem has been solved by using adequate semi-empirical equations (Fedors' equation ${ }^{36}$ modified by Rao, ${ }^{37}$ Heller, ${ }^{38}$ or Wolf ${ }^{39}$ ), already verified for neutral polymers and some polyelectrolytes in water.

We have checked the applicability of these equations and, except Martin's (Eq. 7), the other (Fedors's (Eq. 5), Heller's (Eq. 6)) equations lead to linear plots, which allowed the calculation of intrinsic viscosity for DBAP-P in the dilute regime $\left(\eta_{\mathrm{r}}<2\right)$ :

$$
\begin{aligned}
& \frac{1}{2\left(\eta_{r}{ }^{1 / 2}-1\right)}=\frac{1}{[\eta] C}-\frac{1}{[\eta] C_{\max }} \\
& \frac{1}{2}\left(\frac{1}{\eta_{s p}}+\frac{1}{\ln \left(1+\eta_{s p}\right)}\right)=\frac{1}{C[\eta]}-K_{H e} \\
& \eta_{s p}=C[\eta]^{\exp }{ }^{\left(K_{M} C[\eta]\right)} \\
& \ln \eta_{r}=\frac{C[\eta]_{W}+B C^{2}[\eta]_{W}[\eta]^{*}}{1+B C[\eta]_{W}}
\end{aligned}
$$

where $K_{\mathrm{He}}, K_{\mathrm{M}}$ are constants describing the interactions in solution. The concentration parameter $C_{\max }$ has the dimensions of concentration and indicates the upper limit of concentration above which the polymer solution does not flow anymore. ${ }^{6}$

Figure $4 \mathrm{a}$ shows the evaluation of the experimental data according to the Fedors equation, for which a very good linear correlation with $\mathrm{R}^{2}=0.9988$ was obtained. Wolf's approach allowed determining the intrinsic viscosity of the DBAP-P aqueous solutions for the entire concentration regime studied. One can observe that the curve calculated according to Equation (8) (line from Fig. 4b) coincides very well with the experimental data and this confirms that Wolf's approach is appropriate to describe the viscometric behavior of DBAP-P in water.

In the Wolf equation (8), $B$ represents an interaction parameter having the same physical meaning as $K_{\mathrm{H}}$ (Huggins' constant), and [ $\left.\eta\right]^{\bullet}$ is the specific characteristic hydrodynamic volume. In the case of polyelectrolytes solutions, the magnitude of $B$ is given by the contributions of both Coulombic interactions and Van der Waals forces. ${ }^{40}$ For the DBAP-P sample, the value of $B$ is positive and higher than that found for native pullulan (0.101) by Spatareanu et al. ${ }^{41}$ Therefore, the contribution of Coulombic interactions is significant, compared with the non-Coulombic ones.

Table 1 summarizes the values of the viscometric parameters for DBAP-P solutions 
evaluated by using Equations (5)-(7), and the critical concentration at which polymer coils begin to overlap, $C^{*}$, was determined as $1 /[\eta]{ }^{42}$ Since $[\eta]$ calculated by the three equations was identical, in Table 1, only the viscosimetric parameters calculated by Fedors' and Wolf's equations are presented.

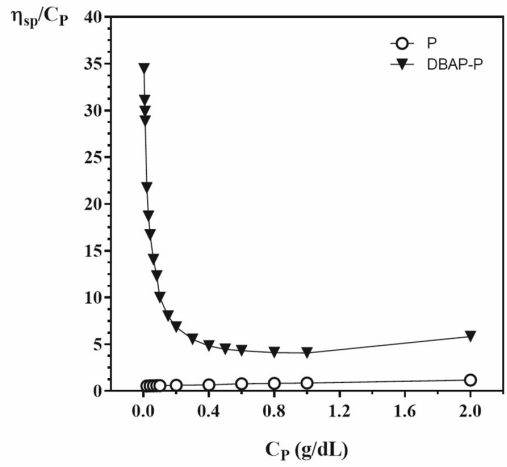

Figure 3: Huggins plots for pullulan and amphiphilic polyelectrolyte (DBAP-P) in dilute and semi-dilute aqueous solutions
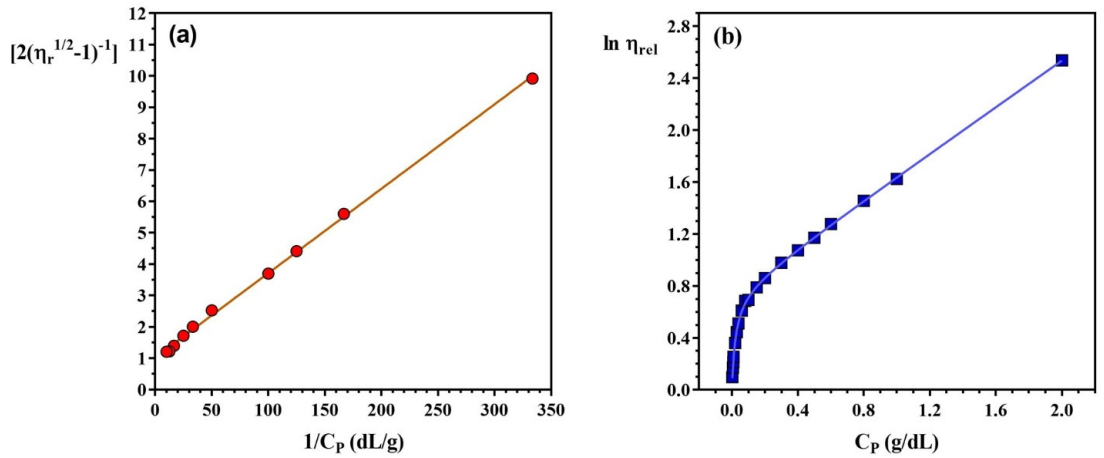

Figure 4: Fedors (a) and Wolf (b) plots for DBAP-P amphiphilic polyelectrolyte in dilute and semi-dilute aqueous solutions

From Table 1, we can observe that $C^{*}$ calculated as $1 /[\eta]$ is smaller than $C^{*}$ determined as $C$ at $\eta_{\mathrm{sp}} \sim 1$. A reason could be the differences between the amphiphilic polymer chain conformation in the very dilute regime and at finite dilution. In fact, at finite dilution, the influence of intramolecular hydrophobic interactions could result in a more compact structure, in comparision with a quite stretched coil conformation at infinite dilution due to the stronger electrostatic repulsions.

For a better quantification of the interplay between electrostatic and hydrophobic interactions over the entire concentration domain studied, specific viscosity $v s$ concentration profile was obtained for the DBAP-P aqueous solutions (Fig. 5a). According to the scaling theory elaborated for polyelectrolytes and neutral polymers, the variation of $\eta_{\mathrm{sp}}$ with $C \mathrm{p}$ is expressed by power-law functions $\left(\eta_{\mathrm{sp}} \sim C_{\mathrm{P}}{ }^{\mathrm{n}}\right), n$ values discriminating among different concentration regimes. ${ }^{43}$ The viscosity scaling relationships for the polyelectrolyte solutions in the dilute, semidilute unentangled, semidilute entangled, and concentrated regimes are as follows: ${ }^{44}$

$\eta \sim C^{1}$ for $C_{\mathrm{P}}<C^{*}$

$\eta \sim C^{0.5}$ for $C^{*}<C<C_{\mathrm{e}}$

$\eta \sim C^{1.5}$ for $C_{\mathrm{e}}<C<C_{\mathrm{D}}$

$\eta \sim C^{3.75}$ for $C>C_{\mathrm{D}}$

In the dilute regime $(C<0.015 \mathrm{~g} / \mathrm{dL})$, the DBAP-P polymer showed an atypical power law $\left(\mathrm{n}_{1} \sim 0.85\right)$, what could be a proof for the intramolecular hydrophobic interactions effectively acting in this domain. When $C>0.015$ $\mathrm{g} / \mathrm{dL}$, the formed micelles and other polymer coils 


\section{Marieta Constantin et al.}

begin contacting each other statically. This concentration corresponds to the critical overlap concentration $\left(C^{*}\right)$. At $0.014<C<0.55 \mathrm{~g} / \mathrm{dL}$ polymer concentration, the ion density increases and the electrostatic repulsion between the polymer chains also increases. Meanwhile, the intermolecular association is enhanced further. In this regime, the increase of $\eta_{\mathrm{sp}}$ slows down $\left(\mathrm{n}_{2} \sim 0.49\right)$ because the size of the polyelectrolyte reduces, which is caused by a much stronger electrostatic repulsion from surrounding polyelectrolytes. Despite its typical polyelectrolyte behavior in this regime, the width of the unentangled regime is narrower $\left(C \mathrm{e} / C^{*} \sim 37\right)$ than that reported by Dou and Colby $^{43}$ for hydrophilic polyelectrolytes $\left(C \mathrm{e} / C^{*} \sim 1000\right)$. This is the result of an increasing preponderance of hydrophobic intra- and intermolecular associations over electrostatic interactions. When $C>0.55 \mathrm{~g} / \mathrm{dL}\left(C_{\mathrm{e}}\right)$, the polymer chains begin entangling together and the high ion intensity makes the polyelectrolytes act like a neutral polymer, and, as a result, the dimensions of the polyelectrolytes are restored to normal again.

The $\eta_{\mathrm{sp}}$ vs $C_{\mathrm{p}}$ plots show a slope variation around $0.08 \mathrm{~g} / \mathrm{dL}$, which can be due to its low tendency to aggregate at this concentration. Moreover, this point can be associated with the aggregate formation tendency of the polymer, since it coincides with the cac determined by the fluorescence studies in the presence of pyrene (Fig. 5a).

Table 1

Values of intrinsic viscosity determined by Eqs. 5 and 8, viscosimetric parameters of Wolf's equation, critical overlap concentration for DBAP-P sample in aqueous solutions at $25^{\circ} \mathrm{C}$

\begin{tabular}{cccccccc}
\hline $\begin{array}{c}{[\eta]_{F}} \\
(\mathrm{dL} / \mathrm{g})\end{array}$ & $\begin{array}{c}C_{\max } \\
(\mathrm{g} / \mathrm{dL})\end{array}$ & $\begin{array}{c}{[\eta]_{\mathrm{W}}} \\
(\mathrm{dL} / \mathrm{g})\end{array}$ & $B_{\mathrm{W}}$ & {$[\boldsymbol{\eta}]_{W}^{*}$} & \multicolumn{2}{c}{$C^{*}(\mathrm{~g} / \mathrm{dL})$ determined by } & \multirow{2}{*}{\begin{tabular}{c}
$C^{*}(\mathrm{~g} / \mathrm{dL})$ \\
\cline { 5 - 7 }
\end{tabular}} \\
\hline 37.17 & 36.5 & 34.41 & 1.283 & 0.89 & 0.0269 & 0.029 & 0.1 \\
\hline
\end{tabular}
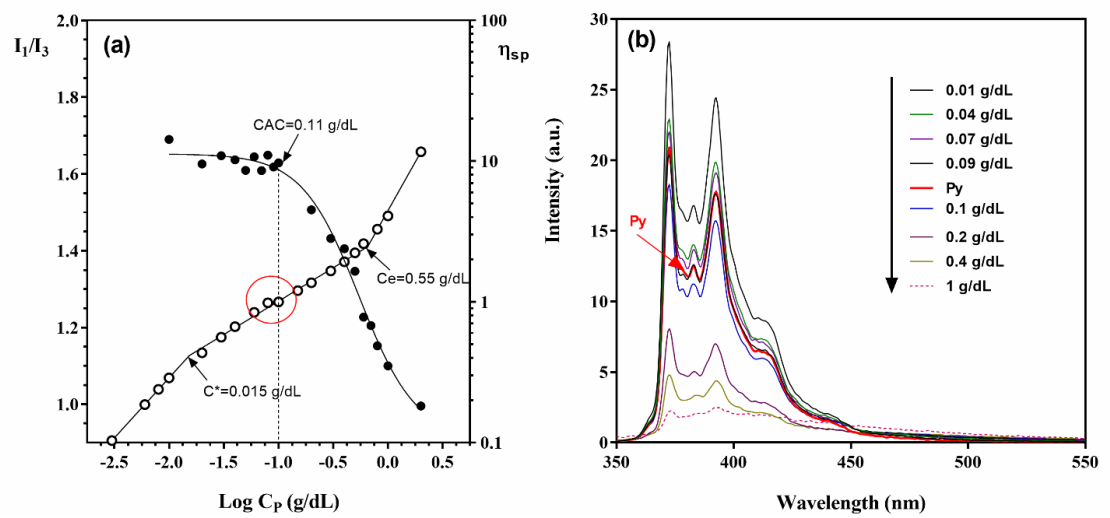

Figure 5: Variation of pyrene polarity parameter $\mathrm{I}_{1} / \mathrm{I}_{3}$ (full symbols) and specific viscosity $\eta_{\text {sp }}$ (open symbols) with polymer concentrations (a); Variation of fluorescence intensity of Py in the presence of DBAP-P at different concentrations (b)

\section{Self-aggregates of DBAP-P in aqueous solution}

It is well known that the variation of the fluorescence intensity ratio for peaks I/III of pyrene, the so-called polarity parameter, is quite sensitive to the polarity of the microenvironment where pyrene is located. $^{45,46}$

The evolution of the fluorescence intensity of Py and of the ratio $I_{1} / I_{3}$ against the logarithm of
DBAP-P concentration is presented in Figure 5. The fluorescence intensity decreases as polymer concentration increases (Fig. 5b) and the $\mathrm{I}_{1} / \mathrm{I}_{3}$ ratio decreases with reducing polarity (Fig. 5a). In the region of low concentrations $(0.01-0.08 \mathrm{~g} / \mathrm{dL})$, the $I_{1} / I_{3}$ values remain fairly constant and correspond to a very polar medium, which suggests that Py is exposed to water. However, these values are 
lower than the value measured for Py in aqueous solution (1.67), which means that the DBAP-P, even at low concentrations, modifies the environment sensed by pyrene. At a particular DBAP-P concentration, the value $\mathrm{I}_{1} / \mathrm{I}_{3}$ significantly decreases, due to the transfer of Py to a less polar and hydrophobic domain. This breaking point corresponds to the concentration at which the micelles start to aggregate (critical aggregation concentration, $\mathrm{cac}$ ) and it is $\sim 0.11$ $\mathrm{g} / \mathrm{dL}$ for DBAP-P. At the highest polymer concentration $(2 \mathrm{~g} / \mathrm{dL})$, the $\mathrm{I}_{1} / \mathrm{I}_{3}$ value is 0.98 . A similar value has been obtained in aqueous solutions of poly(methacrylic acid), ${ }^{47}$ polystyreneb-poly(tert-butyl methylacrylate), ${ }^{48}$ cationic amphiphilic dextran with pendant quaternary ammonium groups, ${ }^{20}$ and amphiphilic carboxymethylpullulan. ${ }^{49}$

DLS was used to measure the size of the DBAP-P aggregates in aqueous solutions as a function of concentration and temperature, and the results are shown in Figure 6. At $25{ }^{\circ} \mathrm{C}$ (Fig. $6 \mathrm{a})$, in the region of low concentration (0.02 $\mathrm{g} / \mathrm{dL}$ ), the $D_{\mathrm{h}}$ distribution remains close to the unmodified pullulan molecules. ${ }^{41}$ By further increasing the concentration close to cac $(0.1$ $\mathrm{g} / \mathrm{dL})$ or above $c a c(0.5 \mathrm{~g} / \mathrm{dL})$, a bimodal distribution of polymer aggregates was observed, the average size of the aggregates increasing from 670 to $770 \mathrm{~nm}$ with the increase in polymer concentration. Similar results were reported for amphiphilic hydrophobic modified cellulose derivatives $^{50-53}$ and it was suggested that the lower $D_{h}$ region comes from the single molecular chains or the single molecular self-aggregates through the intra-molecular hydrophobic interactions.

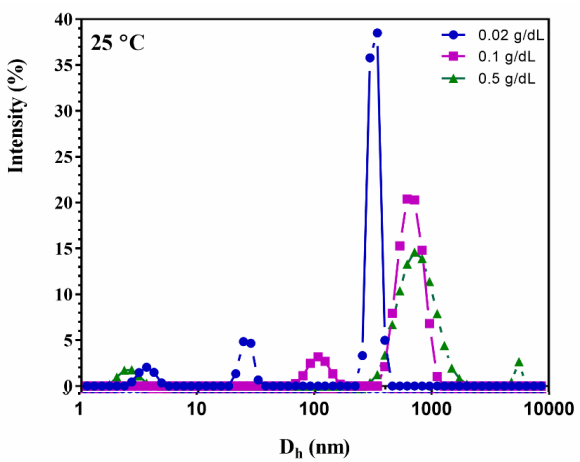

Figure 6: Hydrodynamic diameter of DBAP-P aggregates in distilled water at different concentrations and

temperatures
Besides, the higher $D_{h}$ region is considered to be the area of multiple macromolecular aggregates through the inter-molecular hydrophobic interactions. The increase of temperature to $40{ }^{\circ} \mathrm{C}$ (Fig. 6b) shows, for all three polymer concentrations, evidence of the enhancing of hydrophobic intra- and inter-molecular interactions, since the size and the polydispersity of aggregates decreases about twice. The DLS data are consistent with the viscosity behavior presented in Figure 5a.

\section{Drug loading}

Recently, a new method to obtain chitosan/DNA complexes with well-defined nanostructured morphology by the osmosis process was reported. ${ }^{31}$ This method has the advantage of obtaining DNA-loaded nanospheres without surfactants. In order to see if the DBAP-P polymer has the ability to form polyplexes with DNA, we applied the new patented osmosis-based method $^{54}$ by using the couple solvents watermethanol and by varying the polymer/DNA ratio.

Figure 7 shows the hydrodynamic diameter distribution and the AFM images of DBAP-P and DNA-loaded DBAP-P nanoparticles in distilled water. The intensity averaged DLS curves of $\mathrm{Np} 1$ - Np 2 nanoparticles showed bimodal size distribution, indicating the coexistence of the small nanoparticles of several $\mathrm{nm}$ with large ones. Considering the high size ratio of the large nanoparticles to the small nanoparticles in each suspension, we used number averaged DLS curves to show the size distributions of the asprepared nanoparticles.

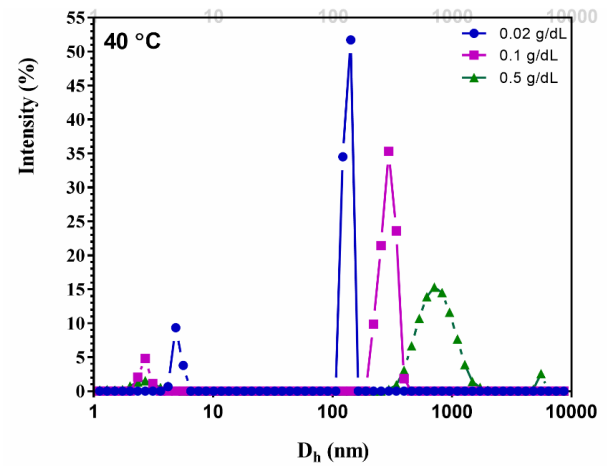



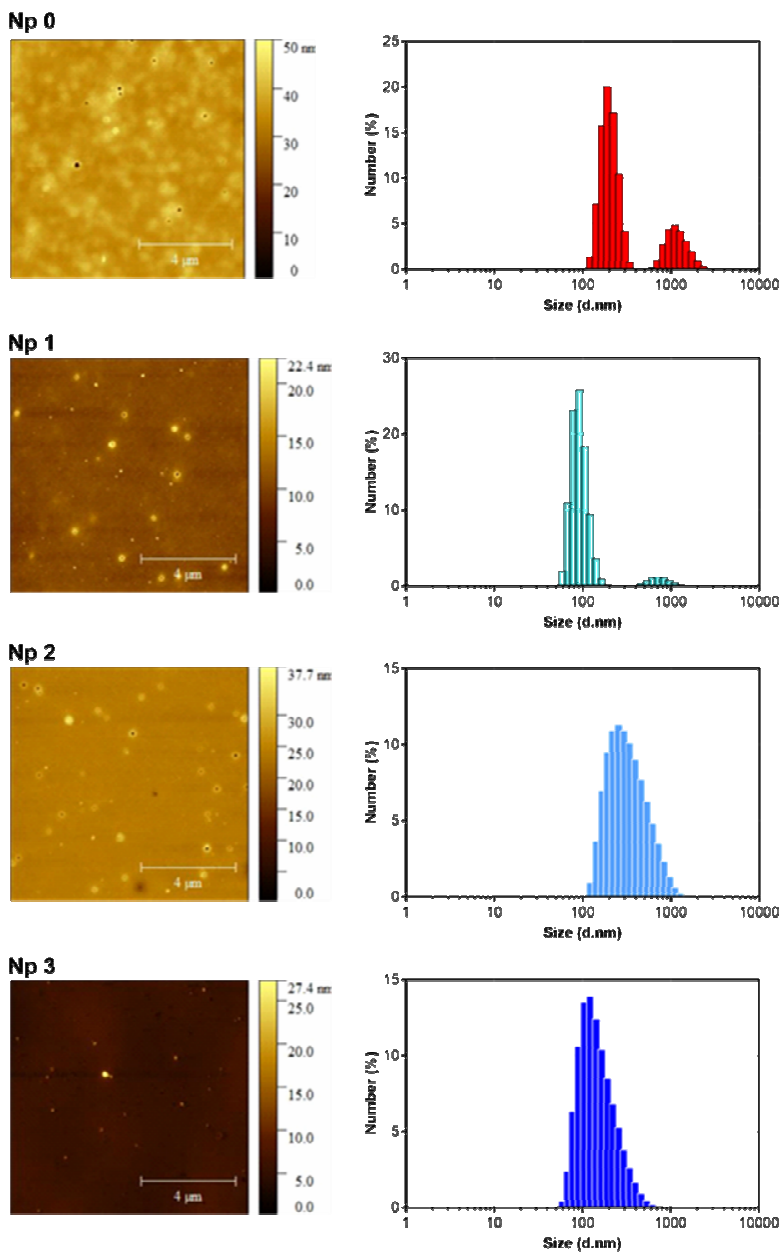

Figure 7: AFM images and size distribution by number obtained by DLS technique for DBAP-P nanoparticles containing DNA

Table 2

Preparation conditions and dimensional characteristics of free and DNA loaded DBAP-P nanoparticles

\begin{tabular}{|c|c|c|c|c|c|c|c|}
\hline $\begin{array}{l}\text { Sample } \\
\text { code }\end{array}$ & $\begin{array}{l}\text { DBAP-P } \\
(\mathrm{mg} / \mathrm{mL})\end{array}$ & $\begin{array}{c}\text { DNA } \\
(\mathrm{mg} / \mathrm{mL})\end{array}$ & $\begin{array}{c}\text { Diameter } \\
(\mathrm{nm})\end{array}$ & $\mathrm{PDI}^{\mathrm{a}}$ & $\begin{array}{c}\zeta \\
(\mathrm{mV})\end{array}$ & $\begin{array}{c}\text { DLC } \\
(\%)\end{array}$ & $\begin{array}{c}\text { Efficiency } \\
(\%)\end{array}$ \\
\hline Np 0 & 5 & 0 & $\begin{array}{c}1214-23 \% \\
202-77 \%\end{array}$ & 0.724 & 47 & - & - \\
\hline Np 1 & 5 & 0.4 & $\begin{array}{l}752.2-6 \% \\
93.5-94 \%\end{array}$ & 0.609 & 36.4 & 38.98 & 25 \\
\hline Np 2 & 5 & 1 & 447.6 & 0.689 & 30 & 67.75 & 9 \\
\hline $\mathrm{Np} 3$ & 5 & 2 & 246.3 & 0.310 & 24.7 & 72.28 & 11 \\
\hline
\end{tabular}

${ }^{\mathrm{a}} \mathrm{PDI}=$ polydispersity index

The average size of DBAP-P particles was $1157 \mathrm{~nm}$ with a bimodal distribution, the major fraction being about $200 \mathrm{~nm}$. For DBAP-P/DNA nanoparticles, a value of $246 \mathrm{~nm}$ was obtained for a DBAP-P/DNA ratio of $5 / 2$, with a maximum in the size distribution curve at $162 \mathrm{~nm}$ and a polydispersity index of 0.31 (Table 2). As can be seen in Table 2, by increasing the amount of DNA (DBAP-P/DNA ratio from 5:0.4 to 5:2), the average size and polydispersity of the nanoparticles decreased. Also, the decrease of the zeta potential value by increasing the amount of DNA in the nanoparticles confirmed the capacity of DBAP-P to encapsulate DNA molecules. 
The AFM images presented in Figure 7 show that the nanoparticles obtained by osmosis have a spherical shape.

\section{In vitro cytotoxicity tests}

Cytotoxicity is an important factor for the application of drug carriers in human body. In this work, MTT assay was performed to investigate the cytotoxicity of DBAP-P and DNA-loaded DBAP-P nanoparticles on primary albino rabbit dermal fibroblasts. Figure 8a shows the survival rates of cells treated with DNA-loaded DBAP-P nanoparticles (Sample Np 3 in Table 2). The cytotoxicity of free DBAP-P nanoparticles was high, even at low concentration, because of their relatively great content of cationic groups, which can damage the cellular membrane (data not shown). Instead, the viability of the cells treated with various concentrations of $\mathrm{Np} 3$ was $80 \%$ for the smallest concentration. Moreover, cell viability remained unchanged during the 72 hours of incubation in the presence of $25 \mu \mathrm{g} / \mathrm{mL}$ of nanoparticles. Figure $8 \mathrm{~b}$ shows images of cell culture in the presence of free and DNA-loaded DBAP-P nanoparticles, after 72 hours of incubation. The cells appeared healthy in the presence of $25 \mu \mathrm{g} / \mathrm{mL}$ of $\mathrm{Np} \mathrm{3}$, having the same morphology as those from the control cultures.

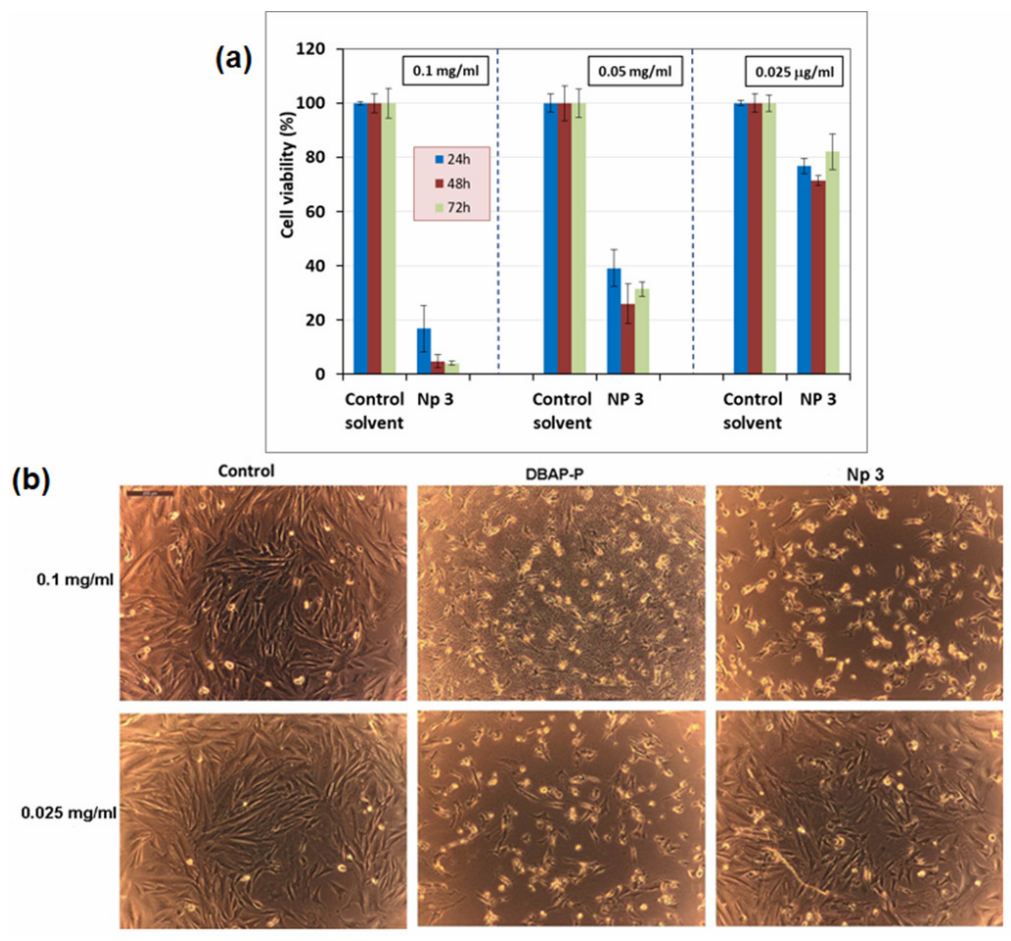

Figure 8: (a) In vitro cytotoxicity of DNA loaded DBAP-P nanoparticle suspensions (Np 3 in Table 2) against primary albino rabbit fibroblasts; (b) Confocal microscopy images of cells in the absence and in the presence of different concentrations of free and DNA-loaded DBAPA-P nanoparticle suspensions

\section{CONCLUSION}

Cationic and amphiphilic pullulan derivative (DBAP-P) was successfully synthesized by introducing (dibutylamino)propyl carbamate groups to the hydroxyl groups of pullulan. The cac value of the pullulan derivative was quite high $(0.1 \mathrm{~g} / \mathrm{dL})$, since the polymer has a strong polyelectrolyte behavior in aqueous solution, the hydrophobicity of the newly introduced cationic groups being moderate. The polymer was able to self-assemble into nano-scaled polymeric aggregates, with a bimodal size distribution. The size of the aggregates at $25{ }^{\circ} \mathrm{C}$ was between 670 $\mathrm{nm}$ and $770 \mathrm{~nm}$, depending on the polymer concentration. The increase in the temperature to $40{ }^{\circ} \mathrm{C}$ reduced the size (about twice) and the polydispersity of the aggregates. Finally, the DBAP-P/DNA nanoparticles with spherical shape, prepared following the osmosis-based method verified for chitosan/DNA polyplexes, were able to entrap DNA with great efficiency (25\%), as compared to chitosan. The nanoparticulate complex obtained at a DBAPP/DNA weight ratio of $5 / 2$ had a diameter of 
around $240 \mathrm{~nm}$ and showed low toxicity, compared to the cationic pullulan derivative.

ACKNOWLEDGEMENT: The authors acknowledge the financial support of this research through the project "Partnerships for knowledge transfer in the field of polymer materials used in biomedical engineering" ID_40_443, Contract no. 86/8.09.2016, MY SMIS 105689, co-financed by the European Regional Development Fund by the Competitiveness Operational Programme 20142020, Axis 1 Research, Technological Development and Innovation in support of economic competitiveness and business development, Action 1.2.3 Knowledge Transfer Partnerships.

\section{REFERENCES}

1 Y. Nagasaki, K. Yasugi, Y. Yamamoto, A. Harada and K. Kataoka, Biomacromolecules, 2, 1067 (2001), https://doi.org/10.1021/bm015574q

2 C. Martin, N. Aibani, J. F. Callan and B. Callan, Ther. Deliv., $\quad 7, \quad 15 \quad$ (2016), https://doi.org/10.4155/tde.15.84

3 A. San Juan, H. Hlawaty, F. Chaubet, D. Letourneur and L. J. Feldman, J. Biomed. Mat. Res. A, 82, 354 (2007), https://doi.org/10.1002/jbm.a.31062

4 L. Alupei, G. Lisa, A. Butnariu, J. Desbrieres, A. N. Cadinoiu et al., Cellulose Chem. Technol., 51, 631 (2017),

http://www.cellulosechemtechnol.ro/pdf/CCT78(2017)/p.631-649.pdf

F. C. MacLaughlin, R. J. Mumper, J. J. Wang, J. M. Tagliaferri, I. Gill et al., J. Control. Release, 56, $259 \quad$ (1998), https://doi.org/10.1016/s01683659(98)00097-2

6 D. Vandamme, I. Foubert, B. Meesschaert and K. Muylaert, J. Appl. Phycol., 22, 525 (2010), https://doi.org/10.1007/s10811-009-9488-8

7 L. Ghimici, M. Constantin and G. Fundueanu, $J$. Hazard. Mater., 181, $351 \quad$ (2010), https://doi.org/10.1016/j.jhazmat.2010.05.017

8 L. Ghimici and M. Nichifor, J. Macromol. Sci. B. Phys., 48, $106 \quad$ (2009), https://doi.org/10.1080/00222340802561631

9 X. Jiulin and P. L. Dubin, J. Chromatogr., 667, 311 (1994), https://doi.org/10.1016/0021-9673(94)89081-1

10 C. Tribet and F. Vial, Soft Matter., 4, 68 (2008), https://doi.org/10.1039/b708431p

11 E. Faizuloev, A. Marova, A. Nikonova, I. Volkova, M. Gorshkova et al., Carbohyd. Polym., 89, 1088 (2012), https://doi.org/10.1016/j.carbpol.2012.03.071

12 W. Y. Kuo and H. M. Lai, Carbohyd. Polym., 75, 627

(2009),

https://doi.org/10.1016/j.carbpol.2008.09.004
13 M. Nichifor, M. C. Stanciu and B. C. Simionescu, Carbohyd. Polym., 82, $965 \quad$ (2010), https://doi.org/10.1016/j.carbpol.2010.06.027

14 Y. Song, Y. Sun, X. Zhang, J. Zhou and L. Zhang, Biomacromolecules, $\quad 9, \quad 2259 \quad$ (2008), https://doi.org/10.1021/bm800429a

15 Z. Souguir, S. Roudesli, E. L. Picton, D. Le Cerf and E. About-Jaudet, Eur. Polym. J., 43, 4940 (2007), https://doi.org/10.1016/j.eurpolymj.2007.09.017

16 M. Constantin, I. Asmarandei, A. Filimon and G. Fundueanu, High Perform. Polym., 27, 625 (2015), https://doi.org/10.1177/0954008315584182

17 A. Ebringerová, Z. Hromádková, M. Kauráková and M. Antal, Carbohyd. Polym., 24, 301 (1994), https://doi.org/10.1016/0144-8617(94)90075-2

18 A. Geresh, R. P. Dawadi and S. M. Arad, Carbohyd. Polym., 63, $75 \quad$ (2000), https://doi.org/10.1016/s0144-8617(99)00194-0

19 R. Auzély-Velty and M. Rinaudo, Int. J. Biol. Macromol., $\quad 31, \quad 123 \quad$ (2003), https://doi.org/10.1016/s0141-8130(02)00072-7

20 M. Nichifor, S. Lopes, M. Bastos and A. Lopes, $J$. Phys. Chem. B, 108, $16463 \quad$ (2004), https://doi.org/10.1021/jp047267v

21 J. Desbrieres, Polymer, 45, 3285 (2004), https://doi.org/10.1016/j.polymer.2004.03.032

22 Q. He, J. Guan, M. Jing, S. Huang, C. Xu et al., Afr. J. Pharm. Pharmacol., 6, 3285 (2012), https://doi.org/10.5897/ajpp12.1427

23 M. Rekha and P. Chandra, Trends Biomater. Artif. Organs, 20, $116 \quad$ (2007), http://medind.nic.in/taa/t07/i1/taat07i1c.shtml

${ }^{24}$ L. F. Zemljič, N. P. Ulrich, M. Sterniša, S. S. Možina, O. Plohl et al., Cellulose Chem. Technol., 53, 121 (2019), http://www.cellulosechemtechnol.ro/pdf/CCT12(2019)/p.121-132.pdf

25 Y. I. Jeong, J. W. Nah, H. K. Na, K. Na, I. S. Kim et al., Drug Dev. Ind. Pharm., 25, 917 (1999), https://doi.org/10.1081/ddc-100102252

26 M. Gupta and A. K. Gupta, J. Control. Release, 99, 157

https://doi.org/10.1016/j.jconrel.2004.06.016

(2004),

${ }_{27}$ T. Shimizu, T. Kishida, U. Hasegawa, Y. Ueda, J. Imanishi et al., Biochem. Biophys. Res. Commun., 367, 330 (2008), https://doi.org/10.1016/j.bbrc.2007.12.112

28 M. Dionísio, C. Cordeiro, C. Remuñán - López, B. Seijo, A. Rosa da Costa et al., Eur. J. Pharm. Sci., 50, 102 (2013), https://doi.org/10.1016/j.ejps.2013.04.018

29 K. Akiyoshi, S. Kobayashi, S. Shichibe, D. Mix, M. Baudys et al., J. Control. Release, 54, 313 (1998), https://doi.org/10.1016/s0168-3659(98)00017-0

30 H. Hosseinkhani, T. Azzam, Y. Tabata and A. J. Domb, Gene Ther., 11, $194 \quad$ (2004), https://doi.org/10.1038/sj.gt.3302159

31 A. Masotti, F. Bordi, G. Ortaggi, F. Marino and C. Palocci, Nanotechnology, 19, $055302 \quad$ (2008), https://doi.org/10.1088/0957-4484/19/05/055302 
32 F. P. Schwarz, J. Chem. Eng. Data, 22, 273 (1977), https://doi.org/10.1021/je60074a010

33 R. Urbani and A. Cesaro, in "Handbook of Solvents", edited by G. Wypych, ChemTec Publishing, Toronto, New York, 2001, pp. 706-735, https://www.academia.edu/39751472/Handbook_of_so lvents_-_Wypych

34 D. Bruneel, E. Schacht and A. de Bruyn, J. Carbohyd. Chem., 12, $769 \quad$ (1993), https://doi.org/10.1080/07328309308019006

35 M. Nichifor, M. C. Stanciu and B. C. Simionescu, J. Macrom. Sci. B Phys., 49, 983 (2010), https://doi.org/10.1080/00222341003609807

36 R. F. Fedors, Polymer, 20, 225 (1979), https://doi.org/10.1016/0032-3861(79)90226-x

37 M. V. S. Rao, Polymer, 34, 592 (1993), https://doi.org/10.1016/0032-3861(93)90555-o

38 A. Durand, Polym. Eng. Sci., 47, 481 (2007), https://doi.org/10.1002/pen.20722

39 J. Eckelt, A. Knopf and B. A. Wolf, Macromolecules, 41, $912 \quad$ (2008), https://doi.org/10.1021/ma702054f

40 F. Samadi, B. A. Wolf, Y. Guo, A. Zhang and A. D. Schluter, Macromolecules, 41, 8173 (2008), https://doi.org/10.1021/ma801088h

41 A. Spatareanu, M. Bercea, T. Budtova, V. Harabagiu, L. Sacarescu et al., Carbohyd. Polym., 111, 63

https://doi.org/10.1016/j.carbpol.2014.04.060

42 Q. Ying and B. Chu, Macromolecules, 20, 362 (1987), https://doi.org/10.1021/ma00168a023

43 S. Dou and R. H. Colby, J. Polym. Sci. B Phys., 44, 2001 (2006), https://doi.org/10.1002/polb.20853

44 M. Rubinstein, R. H. Colby and A. V. Dobrynin, Phys. Rev. Lett., 73, $2776 \quad$ (1994), https://doi.org/10.1103/physrevlett.73.2776

45 K. Kalyanasundaram and J. K. Thomas, J. Am. Chem. Soc., 99, 2039 (1977), https://doi.org/10.1021/ja00449a004

${ }^{46}$ A. F. Olea, B. Acevedo and F. Martinez, J. Phys. Chem. B, 103, $9306 \quad$ (1999), https://doi.org/10.1021/jp991267r

47 A. F. Olea, H. Rosenbluth and J. K. Thomas, Macromolecules, $\quad 32, \quad 8077 \quad$ (1999), https://doi.org/10.1021/ma990470h
48 A. F. Olea, P. Silva, I. Fuentes, F. Martínez and D. R. Worrall, J. Photochem. Photobiol. A Chem., 217, 49 (2011), https://doi.org/10.1016/j.jphotochem.2010.09.015

49 W. Henni-Silhadi, M. Deyme, M. Ruiz de Hoyos, D. Le Cerf, L. Picton et al., Colloid Polym. Sci., 286, 1299 (2008), https://doi.org/10.1007/s00396-0081896-9

50 Y. Song, L. Zhang, W. Gan, J. Zhou and L. Zhang, Colloid. Surf. B, 83, $313 \quad$ (2011), https://doi.org/10.1016/j.colsurfb.2010.11.039

51 Y. Cao, H. Li, J. Zuo and A. Niu, Acta Polym. Sin., 3, 345

(2000), http://en.cnki.com.cn/Article_en/CJFDTOTALGFXB200003018.htm

52 H. Kang, W. Liu, B. He, D. Shen, L. Ma et al., Polymer, 47, 7927 (2006), https://doi.org/10.1016/j.polymer.2006.09.017

53 L. Yang, J. Kuang, Z. Li, B. Zhang, X. Cai et al., Cellulose, $\quad \mathbf{1 5}, \quad 659 \quad$ (2008), https://doi.org/10.1007/s10570-008-9218-4

54 C. Palocci, M. V. Russo, C. M. A. Belsito, E. Cernia, R. D'Amato et al., PCT Int. Appl., WO2006051572, 1 (2006), https://patentscope.wipo.int/search/en/detail.jsf 